\title{
Dynamic Young's modulus and glass transition temperature of selected tropical wood species
}

\begin{abstract}
Dynamic Young's modulus (E d) of selected tropical wood species, namely Dyera polyphylla, Endospermum diadenum, Cratoxylum arborecens, Alstonia pneumatophora, Macaranga gigantea and Commersonia bartramia, used for the study was measured using the freeï free flexural vibration method. Young's modulus from three point bending (E 3pb) and compression parallel to grain $(\mathrm{E} \mathrm{cp})$ was also studied. The results show that the relationship between $\mathrm{E} \mathrm{d}$ and $\mathrm{E} 3 \mathrm{pb}$ for all wood species is very significant with the mean value of $\mathrm{E} d$ consistently larger than or sometime equal to E 3pb. Surprisingly, the relationship between E $\mathrm{d}$ and $\mathrm{E} \mathrm{cp}$ is not significant except for Alstonia pneumatophora. The dynamic mechanical thermal properties were also investigated using the dynamic mechanical thermal analyser (DMTA). The results showed that the storage modulus of the wood species at $190^{\circ} \mathrm{C}$ is in the range of $1.48 \mathrm{i} 4.09 \mathrm{GPa}$ with a glass transition temperature ranging from 50 to $70^{\circ} \mathrm{C}$.
\end{abstract}

Keyword: Compressive Young's modulus; Dynamic Young's modulus; Glass transition temperature; Loss tangent; Storage modulus; Three point bending Young's modulus 